\title{
MULHER E ESCRITURA: PRODUÇÃO LETRADA E EMANCIPAÇÃO FEMININA NO BRASIL
}

\author{
Constância Lima Duarte (UFMG)
}

\begin{abstract}
Por que a ciência nos é inútil? Porque somos excluídas dos encargos públicos. E por que somos excluídas dos cargos públicos? Porque não temos ciência (Nísia Floresta, 1832).
\end{abstract}

RESUMO: Este ensaio apresenta um panorama de como o feminismo influenciou a produção da escritora brasileira nos séculos XIX e XX. Pensamos feminismo como toda ação realizada por uma ou mais mulheres, que tenha como objetivo a ampliação dos direitos civis e políticos ou a equiparação de seus direitos com os do homem. Dividimos as influências do feminismo na cultura brasileira em quatro momentos de mudanças ideológicas ou sociais para as mulheres: 1830, 1870, 1920 e 1970. Com isso, ressaltamos o quanto esse movimento contribuiu para a modernização do Brasil.

PALAVRAS-CHAVE: feminismo, literatura brasileira, história das mulheres.

ABSTRACT: This essay presents an overview of how the feminism influenced the production of Brazilian writers in the XIX and XX centuries. We believe feminism is any action undertaken by one or more women, which has as objective the expansion of civil and political rights or the assimilation of their rights with the masculine ones. We divided the influences of feminism in Brazilian culture in four moments of ideological or social changes for women: 1830, 1870, 1920 and 1970. Thereby, we emphasize how this movement has contributed to the modernization of Brazil.

KEY-WORDS: feminism, Brazilian literature, history of women.

As reflexões que aqui proponho são fruto de um projeto intitulado "Literatura e Feminismo no Brasil: trajetórias e diálogos”, que ora desenvolvo. A ideia é antiga, e creio que sempre esteve no meu trabalho, pois, sempre que investigava o percurso das mulheres na literatura, tentava vislumbrar aspectos comuns com a história do movimento feminista, e representativos de um possível diálogo entre eles.

Começo esclarecendo o que entendo por feminismo. Na maioria das vezes, feminismo é compreendido apenas como um movimento articulado de mulheres em torno de determinadas bandeiras, como o voto, por exemplo. Prefiro pensar em "feminismo" em um sentido mais amplo, como toda ação realizada por uma ou mais mulheres, que tenha como objetivo a ampliação dos direitos civis e políticos ou a 
equiparação de seus direitos com os do homem. Somente assim será possível valorizar os momentos iniciais desta luta - contra os preconceitos mais primários e arraigados - e considerar as primeiras mulheres como precursoras e legítimas feministas.

E, após ler e reler as escritoras, e pensar na trajetória da literatura de autoria feminina concomitante à do movimento feminista, quero sugerir a existência de, pelo menos, quatro momentos comuns nessa trajetória. Com certeza, eles não aconteceram isoladamente, nem independentes uns dos outros. Ao contrário, se complementam como se o seguinte fosse a continuação do anterior, que veio antes apenas para preparar o terreno... Também gosto de pensar nestes momentos como ondas, que se formam de maneira difusa, se avolumam até o clímax, para então refluir numa fase de aparente calmaria.

As décadas em que estes momentos-ondas teriam obtido maior visibilidade, isto é, em que estiveram mais próximos da concretização de suas bandeiras, seriam 1830, 1870, 1920 e 1970. Ou seja, foram necessários cerca de cinquenta anos entre um e outro, com certeza ocupados por um sem número de pequenas movimentações e de nomes de mulheres. Em cada um deles, para efeito de ilustração, identifico algumas escritoras.

Primeira onda: ensinando o bê a bá

Ora, sabemos que, nas primeiras décadas do século XIX, as mulheres brasileiras, em sua enorme maioria, viviam enclausuradas em preconceitos e imersas em uma indigência cultural inacreditável. A herança moura trazida nas caravelas resistia e impunha uma vida de reclusão, ignorância e submissão. Urgia levantar a primeira bandeira, que não podia ser outra senão o direito à educação: aprender a ler, a escrever e ter noções de aritmética. A maioria das pessoas achava que bastava à menina saber bordar, cozinhar, tocar piano. A primeira legislação autorizando a abertura de escolas públicas femininas data de 1827 , e até então havia apenas uns poucos conventos que guardavam as meninas para o casamento, escolas particulares nas casas das professoras, e a opção do ensino individualizado, preferido pelas famílias de mais posses. E foram as primeiras 'mulheres educadas' de então que tomaram para si a tarefa de estender as benesses do conhecimento às demais companheiras, abrindo escolas, publicando livros, 
enfrentando a opinião corrente que insistia em dizer que mulher não necessitava aprender ler e muito menos escrever.

O nome que se destaca é o de Nísia Floresta Brasileira Augusta (1810-1885), nascida no Rio Grande do Norte, e que residiu em Recife, Porto Alegre e Rio de Janeiro, antes de se mudar para a Europa. Seu primeiro livro - Direitos das mulheres e injustiça dos homens, de 1832 - foi também o primeiro entre nós a tratar dos direitos das mulheres à instrução, e ao trabalho, e a exigir que elas fossem respeitadas e consideradas seres inteligentes. Em cada capítulo pode-se quase ouvir os ecos dos famosos artigos da "Declaração dos Direitos da Mulher e da Cidadã", de Olympe de Gouges (1745-1793), publicados em 1791 na França, em resposta à Declaração dos Direitos do Homem, que excluía as mulheres. Inspirando-se em pensadores como Mary Wollstonecraft, Poulain de la Barre e Sophie, Nísia identifica na herança cultural portuguesa as causas do preconceito e ridiculariza a ideia dominante da superioridade masculina.

E aqui está a marca diferenciadora deste momento: a nossa primeira onda (mais que as outras) vem de fora, de além mar, não nasce entre nós. E Nísia Floresta é importante porque traduziu nos dois sentidos: colocou em língua portuguesa o clamor que vinha da Europa; e fez a tradução cultural das novas ideias para o contexto nacional, pensando na mulher e na história brasileira.

Em 1832, eram raras as mulheres brasileiras educadas e, em menor número ainda, as escritoras. A mineira Beatriz Francisca de Assis Brandão (1779-1860), as gaúchas Clarinda da Costa Siqueira (1818-1867) e Delfina Benigna da Cunha (1791-1857), eram algumas dessas exceções hoje conhecidas. Mesmo entre os chamados "jornais femininos", apenas existiam uns poucos periódicos dirigidos por homens atentos às mudanças do comportamento social, e que se apressavam em oferecer publicações especialmente pasteurizadas para o público feminino.

Segunda onda: ampliando a educação e sonhando com o voto

A segunda onda surge por volta de 1870 , e se caracteriza principalmente pelo surgimento espantoso de jornais e revistas de feição nitidamente feminista, em diversas cidades do país. Considero-a, por isso, menos literária e mais jornalística. E são muitos 
os nomes de periódicos. Inicio com O Sexo Feminino, dirigido pela incansável Francisca Senhorinha da Mota Diniz, que circulou em 1873 na cidade de Campanha (MG), e em 1875 na Corte. Com a proclamação da República, seu nome foi mudado para O Quinze de Novembro do Sexo Feminino, e o jornal passou a defender com mais ênfase o direito ao estudo e ao trabalho, e a denunciar o regime de escravidão que muitas mulheres viviam. E tivemos outros, como o Jornal das Damas, de 1874; o Echo das Damas, de 1875, A Mulher, de 1881, que era publicado em Nova York por duas estudantes brasileiras de Medicina, e A Família, de Josefina Álvares de Azevedo.

Todos estes periódicos foram importantes instrumentos na conscientização das mulheres, pois divulgavam o que ocorria nos outros países, faziam circular os textos entre si, davam notícias de livros, da abertura de escolas, e apoiavam as iniciativas das companheiras. Enfim, criaram, concretamente, uma legítima rede de apoio mútuo e de intercâmbio intelectual.

Dentre tantas mulheres desta época destaco Josefina Álvares de Azevedo (1851?), autora de romances, de contos e de textos favoráveis ao divórcio, ao voto e ao ensino superior. Com um discurso inflamado, ela questionava a construção ideológica do gênero feminino e exigia mudanças radicais na sociedade. $O$ jornal que dirigiu, chamado A Família, destacou-se principalmente pelo tom combativo e o firme questionamento da exigência da tutela masculina na vida das mulheres. Como os anteriores, foi também testemunha da resistência feminina e um potente amplificador de vozes que ousavam romper o preconceito e insistiam em afirmar sua presença no mundo. Em 1878, Josefina Álvares conseguiu encenar sua peça $O$ voto feminino, no Teatro Recreio, mais tarde publicada em livro, o que faz dela uma das primeiras mulheres a defender o direito ao voto e à cidadania no país. Ao longo do ano de 1877 ela havia viajado por vários estados, como Pernambuco, São Paulo e Bahia, fazendo palestras e divulgando seu jornal, enquanto lançava uma campanha nacional a favor do sufrágio. Nesta empreitada, conquistou tanto adeptas para suas causas, como inimigos rancorosos que a perseguiram implacavelmente através da imprensa. ${ }^{1}$

O Rio de Janeiro, como capital do Império e centro intelectual do país, concentrou o maior número de periódicos feministas, mas as demais regiões também tiveram seus periódicos, nem por isso menos significativos, como O Corimbo, de Porto Alegre, das 
irmãs Revocata Heloísa de Melo e Julieta de Melo Monteiro. Como o jornal teve uma vida surpreendentemente longa — foi publicado de 1884 até 1944 —, encontra-se em suas páginas a produção literária de várias gerações de escritoras e escritores. Os editoriais, geralmente assinados por Revocata Melo, costumavam trazer veementes apelos a favor do voto, à educação superior e à profissionalização feminina. O Corimbo foi incansável na mobilização das mulheres e na divulgação dos avanços em outros países, sempre incentivando as conterrâneas a fazerem o mesmo.

Também a revista A Mensageira, que circulou na capital paulista de 1897 a 1900, dirigida por Presciliana Duarte de Almeida, esteve no cenário nacional, tanto por sua ampla distribuição como pelas ideias que defendia e as escritoras que nela colaboravam. Praticamente em todos os seus números encontra-se a defesa da educação superior e textos divulgando o feminismo. Movida por uma mesma força e um mesmo idealismo, esta imprensa terminou por criar, concretamente, uma legítima rede de intercâmbio intelectual, e por configurar-se como instrumento indispensável para a conscientização feminina.

\section{Terceira onda: construindo a cidadania}

Com toda esta preparação é de se esperar o tamanho da onda que se segue. O século XX já inicia com uma movimentação inédita de mulheres que se organizam e clamam alto pelo direito ao voto, ao curso superior e de trabalhar também no comércio, nas repartições, nos hospitais e indústrias. Bertha Lutz (1894-1976), formada em Biologia pela Sorbonne, torna-se uma das mais expressivas lideranças na campanha pelo voto feminino e pela igualdade de direitos entre homens e mulheres no Brasil. Incansável nos discursos inflamados e na publicação de textos, Bertha Lutz fundou, com outras companheiras, a Federação Brasileira pelo Progresso Feminino, que se disseminou em praticamente todos os estados e resistiu por quase cinquenta anos.

Outras mulheres também devem ser lembradas, como Leolinda Daltro, que criou em 1917 o Partido Republicano Feminino e liderou uma passeata de mulheres no Rio de Janeiro, chamadas sufragettes pela imprensa, para reivindicar o direito ao voto; e Maria Lacerda de Moura (1887-1945), que era adepta do amor livre e da educação sexual, e 
considerava a instrução condição indispensável para que a mulher pudesse transformar sua vida. Seu livro A mulher é uma degenerada? (1924) teve três edições seguidas, tal a repercussão e a polêmica que alcançou nos meios letrados do país.

No campo literário, as escritoras feministas se destacavam. Em 1921, Rosalina Coelho Lisboa (1900-1975) conquistava o primeiro prêmio no concurso literário da Academia Brasileira de Letras, com o livro Rito pagão, e era saudada pela imprensa, principalmente a mais interessada, como um "triunfo da intelectualidade feminina brasileira”, tal o ineditismo que representava. Rosalina Lisboa tinha sido educada em sua própria casa por professores estrangeiros, e desde cedo colaborava em revistas literárias defendendo a participação da mulher na política, e a igualdade de direitos entre os sexos. Participou do Congresso Feminino Internacional, em 1930, em Porto Alegre, como representante da Paraíba, e foi a primeira mulher a ser designada pelo governo brasileiro para uma missão cultural no exterior, no caso, Montevidéu, em 1932.

Também Gilka Machado (1893-1980) publicou, em 1918, um livro de poemas eróticos, Meu glorioso pecado, logo considerado um escândalo por afrontar a moral sexual patriarcal e cristã. Como poucas escritoras de seu tempo, Gilka promoveu a ruptura dos paradigmas masculinos dominantes e contribuiu para a emancipação da sexualidade feminina. Ao vencer um concurso literário do jornal A Imprensa, então dirigido por José do Patrocínio Filho, teve seu trabalho estigmatizado e considerado "imoral" por críticos mais conservadores. Além de poetisa talentosa, participou dos movimentos em defesa dos direitos das mulheres, principalmente ao lado de Leolinda Daltro, com quem criou o utópico Partido Republicano Feminino, em 1910, quando ainda era remota a ideia do voto, sendo sua segunda-secretária. (Não custa lembrar que as primeiras brasileiras que votaram foram as norte-riograndenses, em 1927. As demais, apenas em 1932).

Outra inesquecível foi Ercília Nogueira Cobra (1891-1938) que, no mesmo ano da Semana de Arte Moderna, 1922, lançou seu primeiro livro, Virgindade inútil novela de uma revoltada, dando início a uma obra polêmica que discute a exploração sexual e trabalhista da mulher, e provocando muita crítica entre os contemporâneos. Ercília publicou, ainda, Virgindade anti-higiênica - Preconceitos e convenções hipócritas (1924) e Virgindade inútil e anti-higiênica - novela libelística contra a sensualidade egoísta dos homens (1931), sendo detida várias vezes pelo Estado Novo, 
por suas ideias.

Fora do eixo do Rio de Janeiro, Mariana Coelho se impõe como a 'Beauvoir tupiniquim', como a chamou Zahidé Muzart, em seu estudo sobre a feminista paranaense. Mariana Coelho publicou A evolução do feminismo: subsídios para a sua história, em 1933, que representa uma lúcida contribuição à história intelectual da mulher brasileira. Além de revelar enorme erudição, pois transita com desenvoltura por diversos campos do conhecimento, ao fazer a retrospectiva do movimento feminista na Europa e no Brasil a autora inaugura uma espécie de feminismo-pacifista, que ainda hoje surpreende.

Impõe-se também falar de Rachel de Queiroz, grande nome da literatura brasileira, que por décadas manteve um público atento e renovado, tanto para seus romances como para sua extensa produção no campo da crônica jornalística. Como outras mulheres, Rachel colocou-se na vanguarda de sua época ao penetrar no mundo das letras, na redação dos jornais e na célula partidária, espaços entranhadamente masculinos. A estreia em livro, ocorrida em 1930, com o romance $O$ Quinze, que trata do drama dos flagelados e de agudas questões sociais, provocou tal impacto nos meios literários que houve até quem duvidasse de sua identidade, como confessou o escritor Graciliano Ramos:

O Quinze caiu de repente ali por meados de 30 e fez nos espíritos estragos maiores que o romance de José Américo, por ser livro de mulher e, o que na verdade causava assombro, de mulher nova. Seria realmente de mulher? Não acreditei. Lido o volume e visto o retrato no jornal, balancei a cabeça:

Não há ninguém com esse nome. É pilhéria. Uma garota assim fazer romance! Deve ser pseudônimo de sujeito barbado.

Depois, conheci João Miguel e conheci Raquel de Queirós, mas ficoume durante muito tempo a idéia idiota de que ela era homem, tão forte estava em mim o preconceito que excluía as mulheres da literatura. Se a moça fizesse discursos e sonetos, muito bem. Mas escrever João Miguel e $O$ Quinze não me parecia natural. ${ }^{1}$

Não era para menos. Na narrativa de $O$ Quinze, por exemplo, ao lado de homens fragilizados pela exploração antiquíssima e à catástrofe da seca, a personagem feminina exibe traços de emancipação e prefere viver sozinha, 'pensando por si', do que aceitar um casamento tradicional. Em João Miguel, são as mulheres do povo que rejeitam a reificação, se entregam à libido e reagem ferindo à faca os homens que as abandonam 
com filhos pequenos. Elódia Xavier, em estudo sobre a trajetória ficcional da escritora, afirma, a propósito de As três Marias, que as personagens representam vários aspectos da condição feminina "como a repressão sexual e a falta de perspectivas existenciais", e que, ao tomarem contato com a realidade "se defrontam com a monotonia e a estreiteza do casamento burguês, como 'destino de mulher', citando Simone de Beauvoir."1 Mas, apesar de tantas personagens roubando a cena ficcional e também de sua própria trajetória de vida, Rachel de Queiroz nunca vai admitir a legitimidade do movimento feminista. E, ironicamente, vai caber a ela, em 1977, inaugurar a Academia Brasileira de Letras.

Termino com Adalzira Bittencourt (1904-1976), advogada, escritora e feminista, que organizou no Palace Hotel do Rio de Janeiro, em 1946, a Primeira Exposição do Livro Feminino, obtendo muita repercussão na imprensa. No ano seguinte, ela repetiu o evento em São Paulo, na Biblioteca Mário de Andrade, reunindo mais de mil livros de quinhentas e sessenta escritoras. Os jornais registraram que pelo menos cem escritoras estiveram presentes, e o enorme sucesso de público. Durante os quinze dias da Exposição, foram realizadas palestras sobre a mulher na história e na música, sobre o divórcio, o papel da imprensa, e a literatura de autoria feminina, entre outras. Adalzira Bittencourt foi uma incansável divulgadora da causa da mulher, sempre preocupada com a construção da memória feminina brasileira.

Quarta onda: ainda construindo a cidadania

E chegamos aos anos setenta. Enquanto em outros países as mulheres se uniam contra a discriminação e pela igualdade de direitos, no Brasil o movimento feminista teve marcas distintas, pois a conjuntura histórica impôs que as mulheres se posicionassem também contra a ditadura militar e a censura, a favor da redemocratização, da anistia e melhores condições de vida. Mesmo assim, ao lado de tudo isso, as mulheres discutiram o direito à sexualidade, ao prazer e ao aborto.

É o momento da onda mais exuberante, que altera radicalmente os costumes e torna as reivindicações um senso comum. Novamente surge uma imprensa dirigida por mulheres. Em 75 é fundado o jornal Brasil Mulher, porta-voz do Movimento Feminino pela Anistia; e, em 76, surge o periódico Nós Mulheres, que se assume enquanto 
feminista e circula por quase três anos. Mais tarde, em 1981, em São Paulo, era criado o Mulherio, por iniciativa de feministas ligadas à Fundação Carlos Chagas, que alcança enorme prestígio nos meios universitários.

Dentre tantas, Rose Marie Muraro (1930) se destaca, por sua coerência e os inúmeros títulos que publicou, inclusive em pleno regime militar. Em 1975, Rose fundou com outras companheiras o Centro da Mulher Brasileira, que pode ser considerada entidade pioneira do novo feminismo nacional.

No campo literário, algumas escritoras se posicionavam frente ao governo ditatorial, revelando com coragem suas posições políticas, como Nélida Piñon, que participou da redação do Manifesto dos 1000 contra a censura e a favor da democracia no Brasil. Em 1981, a escritora lançava o livro Sala de armas, composto de contos aparentemente distintos mas que se estruturavam em torno dos encontros e desencontros amorosos. Mais tarde, Nélida tornou-se a primeira mulher a tomar posse como presidente da Academia Brasileira de Letras, e apenas bem recentemente declarou-se feminista. Inúmeras outras escritoras poderiam ser lembradas pela reflexão que seus textos e personagens suscitam nas leitoras, como Lygia Fagundes Telles, Clarice Lispector, Sônia Coutinho, Hilda Hilst, Helena Parente Cunha, Marina Colasanti, Lya Luft, entre outras, muitas outras.

E, ao longo dos anos 80, um movimento bem articulado no meio acadêmico promoveu a institucionalização dos estudos sobre a mulher na universidade brasileira, como já ocorria nos Estados Unidos e na Europa, através da criação de dezenas de núcleos de estudos, de grupos de estudo, e da organização regular de seminários, colóquios e congressos. São estes encontros sistemáticos que vão impulsionar as publicações e propiciar o surgimento de inúmeras teses e dissertações sobre o tema, legitimando definitivamente esta linha de pesquisa entre nós. Aliás, uma das mais profícuas e atuantes dos últimos tempos, em qualquer área que se observe.

\section{Conclusão}

A partir dos anos noventa, à medida que a revolução sexual era assimilada à vida cotidiana, as bandeiras feministas sofrem com a gradual acomodação da militância e o arrefecimento de uma história que começava a ser escrita. 
Há quem defenda, inclusive, que estes seriam tempos "pós-feministas", pois as reivindicações (teoricamente) estariam atendidas e ninguém ousa negar a presença das mulheres na construção social dos novos tempos. Se o prefixo "pós" pretende significar uma fase posterior ao feminismo - que estaria ultrapassado e fora de moda - não posso concordar com a expressão. Apesar de tantas conquistas nos inúmeros campos de conhecimento e da vida social, persistem nichos patriarcais de resistência. Basta que lembremos do salário inferior, da presença desigual de mulheres em cargos de direção e da ancestral violência que continua sendo praticada com a mesma covardia e abuso da força física. Ou então, o que dizem os fundamentalistas do Vaticano, que condenam o feminismo contemporâneo por "equiparar homens e mulheres e ignorar as diferenças biológicas entre os sexos".

Com certeza vivemos outros e novos tempos: as jovens escritoras já não consideram necessário vincular sua obra com questões específicas das mulheres, e o movimento feminista parece atravessar um necessário e importante período de amadurecimento e reflexão. E nós ficamos aqui, à espera da próxima onda, mesmo sem saber que formato e que dimensões ela poderá ter.

\section{REFERÊNCIAS}

COELHO, Mariana. A evolução do feminismo: subsídios para a sua história. Org. Zahidé L. Muzart. 2 ed. Curitiba: Imprensa Oficial do Paraná, 2002.

DICIONARIO Mulheres do Brasil: de 1500 até a atualidade, biográfico e ilustrado. Org. Schuma Schumaher e Érico Vital Brasil. Rio de Janeiro: Jorge Zahar Editor, 2000.

DUARTE, Constância Lima. Nísia Floresta: vida e obra. Natal: UFRN, 1995.

Feminismo e literatura no Brasil. In Revista Estudos Avançados da USP. n. 49. vol. 17, set./dez. 2003. p. 151-172. (Dossiê Mulher, Mulheres).

MUZART, Zahidé Lupinacci. (Org.) Escritoras brasileiras do século XIX. Antologia. Florianópolis: Editora Mulheres; Santa Cruz do Sul: Edunisc, 1999. 
PINTO, Célia Regina Jardim. Uma história do feminismo no Brasil. São Paulo: Editora Perseu Abramo, 2003.

RECEBIDO EM: 04 de maio de 2011

APROVADO EM: 09 de junho de 2011

Notas:

1 Josefina Álvares de Azevedo publicou A mulher moderna: trabalhos de propaganda (1891); Galeria ilustre:Mulheres célebres (1897); Retalhos (1890). Sobre a autora, recomendo O florete e a máscara, de Valéria Andrade Souto-Maior, (Florianópolis: Editora Mulheres, 2001).

1 Cf. RAMOS, Graciliano. Linhas tortas. São Paulo: Record, 1980; p. 137.

1 Cf. "Trajetória ficcional de Rachel de Queiroz", In Anais do V Seminário Nacional Mulher \& Literatura. (Org. DUARTE, C.L.) p. 86. 